\title{
COMPOSIÇÃO E VARIAÇÃO ESPAÇO-TEMPORAL DA CAPTURA DA FROTA DE TRAINEIRAS ENTRE 1997 E 1999 NO PORTO DE ITAJAÍ, SC
}

\author{
OCCHIALINI, D.S. ${ }^{1} \&$ P.R. SCHWINGEL ${ }^{2}$
}

\author{
Centro de Ciências Tecnológicas da Terra e do Mar - Universidade do Vale do Itajaí \\ (CTTMar/UNIVALI) Rua Uruguai, 458 - Cep: 88.302-202 - Itajaí, SC. \\ Email: ${ }^{1}$ a.terra@terra.com.br ${ }^{2}$ schwingel@cttmar.univali.br
}

\begin{abstract}
RESUMO
A frota de traineiras que desembarca no porto pesqueiro de Itajaí, SC, atua em uma ampla área da costa sudeste-sul do Brasil, concentrando suas atividades na plataforma continental

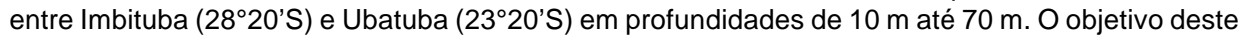
trabalho é verificar a composição da captura e a variação espaço-temporal nos desembarques da frota de traineiras entre 1997 e 1999. Um total de 753 registros de desembarques foram analisados. A plataforma continental foi dividida em 4 setores: Imbituba-Itajaí (setor 5), Itajaí-Cananéia (6), Cananéia-Santos (7) e Santos-Ubatuba (8) e esses subdivididos em profundidades até $40 \mathrm{~m}$ (subsetor a) e de 40 a $80 \mathrm{~m}$ (b). A sardinha-verdadeira (Sardinella brasiliensis) foi a principal espécie capturada em todos os setores, representando uma média de $87 \%$ dos desembarques em 1997 e reduzindo para $40 \%$ em 1999. A sardinha-lage (Opisthonema oglinum) ocorreu nos setores $5 \mathrm{ab}$ e $6 \mathrm{ab}$, representando, em média, $15 \%$ das capturas enquanto a palombeta (Chloroscombrus chrysurus) foi uma espécie capturada exclusivamente em profundidades até $40 \mathrm{~m}$ nos setores, 6 e 7. Essas duas espécies aumentaram sua participação nas capturas ao longo do período analisado. Espécies demersais, como a corvina (Micropogonias furnieri) e o bagre (Netuma spp.), ocorreram exclusivamente nas capturas realizadas em profundidades menores que $40 \mathrm{~m}$ nos setores 5 e 6, apresentando desembarques significativos a partir de 1998. De forma geral, observou-se que o principal setor de captura da frota de traineiras é entre Itajaí e Cananéia (setor 6 ) e que no período analisado a pescaria passou de mono para multiespecífica.
\end{abstract}

Palavras chave: captura, traineira, cerco, porto de Itajaí.

\section{SPATIAL AND TEMPORAL VARIATION OF RELATIVE CAPTURE OF PURSE- SEINING FLEET BETWEEN 1997 AND 1999 IN ITAJAÍ HARBOR, SC}

\footnotetext{
ABSTRACT

The purse seining fleet that lands in Itajaí harbor, SC, fishes in a large region of southern coast off Brazil, concentrating its activities on the continental shelf between Imbituba (28 $\left.20^{\circ} \mathrm{S}\right)$ and Ubatuba $\left(23^{\circ} 20^{\prime} \mathrm{S}\right)$ in depths from $10 \mathrm{~m}$ to $70 \mathrm{~m}$. The objective of the present study is to verify the relative capture of purse-seiners and the spatio-temporal variation of landings between 1997 and 1999. A total of 753 landing records were analyzed. The continental shelf was divided in 4 sectors: Imbituba-Itajaí (sector 5), Itajaí-Cananéia (6), Cananéia-Santos (7) and Santos-Ubatuba (8) and those subdivided in depths up to $40 \mathrm{~m}$ (sub-sector a) and between 40 and $80 \mathrm{~m}$ (b). The Brazilian sardine (Sardinella brasiliensis) was the dominant species captured in all sectors, representing, on average $87 \%$ of the landings in 1997 , and only $40 \%$ in 1999 . The atlantic thread herring (Opisthonema oglinum) occured in the sectors $5 \mathrm{ab}$ and $6 \mathrm{ab}$, and corresponded to $15 \%$ of the captures, while the atlantic bumper (Chloroscombrus chrysurus) was a species captured exclusively in depths up to $40 \mathrm{~m}$ in sectors 6 and 7. Both species increased their participation in the captures between 1997 and 1999. Demersal species, such as white croaker (Micropogonias
} 
furnieri) and catfish (Netuma spp.), occurred exclusively in depths up to $40 \mathrm{~m}$ in sectors 5 and 6 , exhibiting significant landings since 1998. In general, the results suggest that the most important fishing area of the purse-seiners was between Itajaí and Cananéia and that the fishery changed from mono to multispecific in the studied period.

Keywords: capture, purse-seine, Itajaí harbor.

\section{INTRODUÇÃO}

O estado de Santa Catarina, um dos maiores produtores nacionais de pescado, possui uma frota numerosa e diversificada. As capturas desembarcadas no porto de Itajaíl Navegantes, maior do estado, têm mostrado grandes oscilações anuais em termos de desembarque em peso, o que interfere substancialmente na economia local e estadual. Esses municípios destacam-se dentro deste contexto, representando $93 \%$ da produção industrial do estado, dos quais $55 \%$ deste montante é representado pelos desembarques da frota de traineiras (IBAMA, 1994; IBAMA/CEPSUL, 1999). A pesca de traineiras, utilizando redes de cerco, tem como espécie-alvo da frota a sardinha-verdadeira (Sardinella brasiliensis) e caracteriza-se por empregar o maior esforço pesqueiro em termos de número de desembarques anuais (Andrade, 1998).

A sardinha-verdadeira constitui o principal recurso pesqueiro do Brasil, sendo capturada entre Santa Marta $\left(29^{\circ} \mathrm{S}\right)$ e Macaé $\left(22^{\circ} \mathrm{S}\right)$. Em Santa Catarina, os desembarques de sardinha-verdadeira alcançaram a cifra de 67.149 t no ano de 1997; entretanto, esta frota também captura outros recursos pesqueiros, como a sardinha-lage (Ophistonema oglinum) e a palombeta (Chloroscombrus chrysurus), as quais atingiram neste mesmo ano montantes de $691 \mathrm{t}$ e $707 \mathrm{t}$, respectivamente (IBAMA/ CEPSUL, 1999).

Os desembarques totais de sardinhaverdadeira, considerando-se os dados disponíveis para os últimos 36 anos, apresentaram uma tendência ascendente até 1973, quando foi alcançado o pico máximo de 228 mil t (Fig.1). A partir do ano seguinte, a produção entrou em declínio, mostrando dois patamares: entre 1977 e 1980 oscilou em torno de 140 mil t e entre 1983 e 1986, 125 mil t. A partir de 1987, a produção decresceu até atingir apenas 32 mil $t$ em 1990. Em 1991, a produção voltou à crescer, até alcançar o patamar de 105 mil t em 1997. Desde 1998, as estimativas apontam para uma drástica queda nos desembarques. Estimativas para o ano de 1999 e 2000 indicam uma captura aproximada de 20 mil t anuais, o que significaria a menor produção desde o início dos levantamentos estatísticos. Isto se deve provavelmente às condições oceanográficas desfavoráveis que resultaram no insucesso da desova e recrutamento (Nahum et al.,1988; Matsuura,1996 e 1998). Esses fatores ambientais, juntamente com excessivos esforços pesqueiros sobre esse recurso, podem ocasionar quedas nas capturas.

As capturas da frota de traineiras têm mostrado grandes oscilações temporais em termos de desembarque em peso por espécie, o que interfere na economia da região. A queda na produção de sardinha-verdadeira na região sudeste/sul, já se apresentava clara em 1988 , com sinais de esgotamento e de eventual colapso, o que afetou profundamente a atividade do setor pesqueiro sardinheiro nos anos seguintes (Castello \& Haimovici, 1991). Isto acarretou no decréscimo da mão-de-obra empregada e um aumento nas importações para suprir a demanda do mercado. Em 1999 e 2000, a situação foi similar. Várias empresas sediadas nos municípios de Itajaí e Navegantes importaram sardinha oriunda de países como a Venezuela, Mauritânia, Marrocos e Rússia. Além disso, a escassez de sardinha-verdadeira leva a frota a atuar sobre outros recursos, os quais necessitam ser avaliados e estudados 
visando um manejo adequado destes recursos pesqueiros.

O presente trabalho tem como objetivo principal determinar a participação relativa e a distribuição espacial das diferentes espécies capturadas pela frota de traineiras no sudeste/ sul do Brasil, mediante a análise dos desembarques efetuados no porto de Itajaí entre 1997 e 1999.

\section{MATERIAIS E MÉTODOS}

Esse trabalho utilizou dados coletados pelo programa de amostragem do CTTMarUNIVALI entre março de 1997 e dezembro de 1999. Durante as amostragens, são coletados dados de captura, comprimento, peso e parâmetros biológicos por espécie. O desembarque efetuado pela frota de traineiras não sofre nenhum tipo de separação, a bordo ou no cais, permanecendo a sardinha-verdadeira (espéciealvo) junto das espécies acompanhantes. $O$ peso total de cada espécie foi estimado de acordo com a proporção média de cada uma, em peso e/ou número, por caixa amostrada durante o desembarque. Mais detalhes sobre o procedimento amostral efetuado pelo CTTMarUNIVALI podem ser encontrados em Perez et al. (1998).

A área de atuação da frota foi dividida em setores, os quais basearam-se na distribuição do esforço de pesca das diferentes frotas sediadas em Itajaí (e.g. arrasto, cerco, vara e isca-viva) (Pezzuto et al., em prep.). Um total de 4 áreas foram definidas ao longo da costa: setor 5 (Imbituba-Itajaí), setor 6 ( ItajaíCananéia), setor 7 (Cananéia-Santos) e setor 8 (Santos-Ubatuba), os quais foram ainda subdivididos em 2 sub-setores segundo a profundidade, sub-setor "a" (profundidades de até 40 $\mathrm{m}$ ) e sub-setor "b" (profundidades de 41 à 80 m) (Fig.2).

No período analisado foram obtidos 753 registros de desembarques (Tab.1). Em 1997 o esforço amostral foi menor, o que resultou na

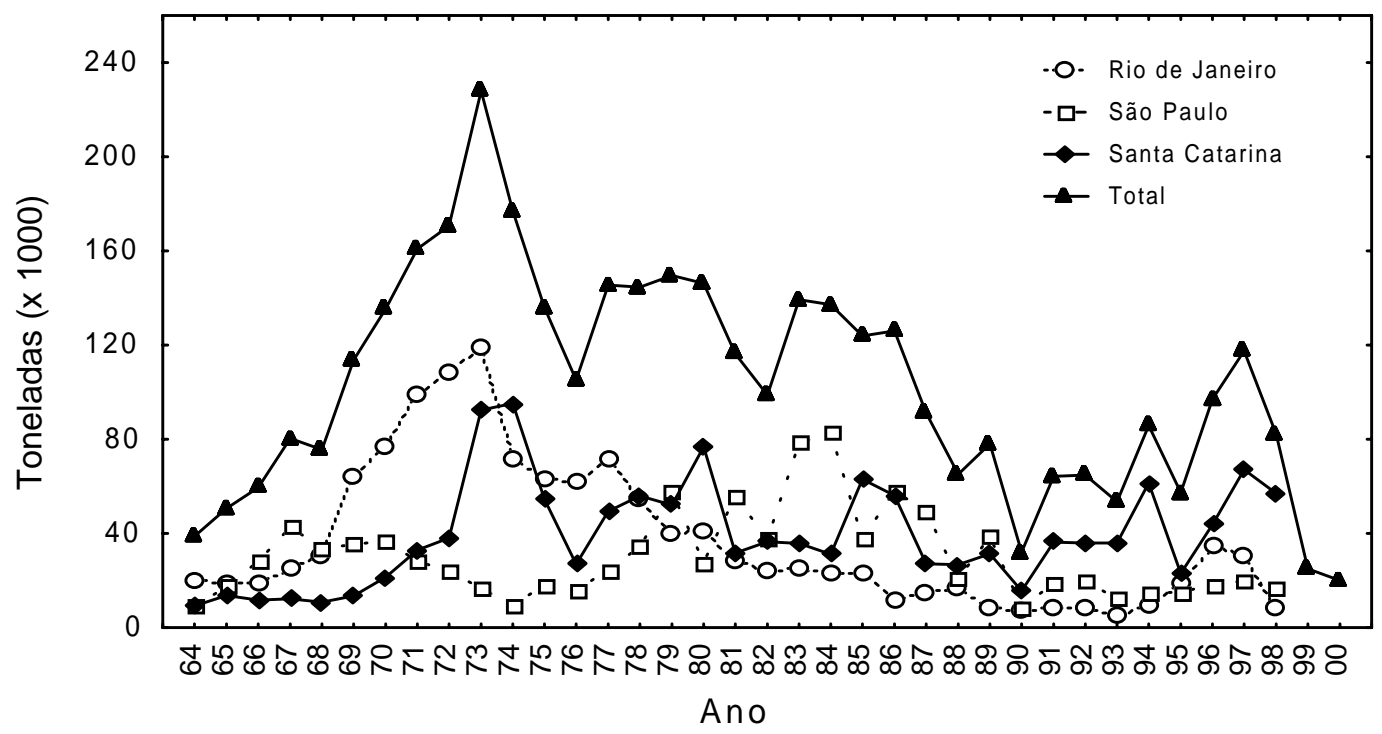

Figura 1: Desembarque anual de sardinha-verdadeira no sudeste do Brasil entre 1964 e 2000. Fonte: IBAMA. Nota: os valores para os anos de 1999 e 2000 são estimativas. 


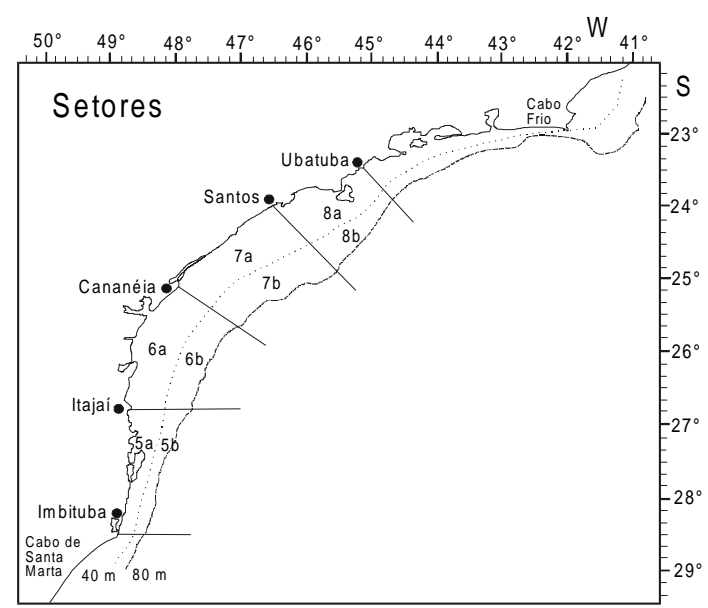

Figura 2: Setores da plataforma continental, onde atua a frota de traineiras que desembarca no porto pesqueiro de Itajaí, SC.

coleta de apenas 112 registros. Devido a um aumento no esforço amostral, foi possível obter 465 registros no ano de 1998, o que implica em uma maior confiabilidade nos resultados derivados destes dados. No ano de 1999 o número de registros diminuiu consideravelmente devido à queda nas capturas da espécie alvo, devendo-se ressaltar que o esforço amostral foi similar ao ano de 1998.

\section{RESULTADOS}

As capturas mostraram a presença de 21 espécies (Tab.2), sendo que destas, as 7 mais importantes e com captura relativa média superior à $0,5 \%$ do total foram analisadas no presente trabalho. As restantes foram agrupadas no item "outras".

\section{Variação Anual das Capturas}

Em 1997, a sardinha-verdadeira predominou nos desembarques, representando uma média mensal de $87 \%$ na composição das capturas (Fig.3a), sendo que no mês de dezembro atingiu a menor proporção do ano (67\%). Este mês caracterizou-se por uma captura significativa de cavalinha (22\%), que alcançou uma média mensal de $7 \%$ no ano. A sardinha-lage também esteve presente nas capturas deste ano, ocorrendo entre junho e outubro, representando uma média mensal de $3 \%$ dos desembarques em peso. A palombeta ocorreu ocasionalmente atingindo nos meses de setembro e outubro, aproximadamente 3\%.

Em 1998 ocorreu uma diminuição da participação de sardinha-verdadeira nas capturas para $72 \%$ (Fig.3b). A captura variou bastante durante o ano, atingindo $73 \%$ dos desembarques no mês de março, sofrendo um incremento para $93 \%$ em abril e reduzindo para $32 \%$ em maio. Este decréscimo na participação de sardinha-verdadeira nas capturas, quando comparado ao ano anterior, está intimamente relacionado com o aumento dos desembarques de sardinha-lage e palombeta, as quais atingiram uma média anual de $13 \%$ e $8 \%$ dos desembarques, respectivamente. A sardinha-lage, ao contrário do ocorrido em 1997, atingiu valores

Tabela 1: Número de desembarques amostrados e sua participação relativa anual entre 1997 e 1999 para os diferentes setores de atuação da frota de traineiras.

\begin{tabular}{|c|c|c|c|c|c|c|c|c|}
\hline \multirow{2}{*}{ SETORES } & \multicolumn{2}{|c|}{1997} & \multicolumn{2}{c|}{1998} & \multicolumn{2}{c|}{1999} & \multicolumn{2}{c|}{ Sub-total (setor) } \\
\cline { 2 - 9 } & número & $\%$ & número & $\%$ & número & $\%$ & número & $\%$ \\
\hline $5 \mathrm{a}$ & 20 & 18 & 57 & 12 & 27 & 15 & 104 & 14 \\
\hline $5 \mathrm{~b}$ & 6 & 5 & 50 & 11 & 7 & 4 & 63 & 8 \\
\hline $6 \mathrm{a}$ & 49 & 44 & 232 & 50 & 115 & 64 & 396 & 53 \\
\hline $6 \mathrm{~b}$ & 4 & 4 & 87 & 19 & 27 & 15 & 118 & 16 \\
\hline $7 \mathrm{a}$ & 8 & 7 & 12 & 3 & 2 & 1 & 22 & 3 \\
\hline $7 \mathrm{~b}$ & 21 & 19 & 13 & 3 & 0 & 0 & 34 & 5 \\
\hline $8 \mathrm{a}$ & 1 & 1 & 2 & 0 & 3 & 2 & 6 & 1 \\
\hline $8 \mathrm{~b}$ & 3 & 3 & 7 & 2 & 0 & 0 & 10 & 1 \\
\hline
\end{tabular}


de capturas consideráveis em março (10\%), e em maio obteve a maior representatividade do ano (48\%). A palombeta também ocorreu durante todo o ano, com participação expressiva na captura de março (16\%), maio (14\%) e novembro (20\%). Neste ano de 1998, apareceram também na captura, entre os meses de agosto e outubro, espécies demersais como a corvina e o bagre, sendo que a primeira atingiu $12 \%$ em setembro e a segunda, $6 \%$ em outubro.

Durante o ano de 1999, a sardinha-verdadeira continuou com uma tendência de queda nas capturas, alcançando $40 \%$ do peso relativo descarregado (Fig.3c). Apenas nos meses de agosto, novembro e dezembro, os desembarques desta espécie atingiram valores elevados (94\%), entretanto, nos meses restantes a participação foi quase sempre inferior à $15 \%$. As capturas de sardinha-lage foram bastante expressivas entre março e julho, quando atingiu até $85 \%$ do total capturado. A palombeta por sua vez, ocorreu expressivamente durante quase todo o ano atingindo uma média de $22 \%$ do total em peso desembarcado. A participação desta espécie atingiu 45\%, 53\% e 99\%

Tabela 2: Lista de espécies capturadas pela frota de traineiras que desembarcaram no porto de Itajaí, entre 1997 e 1999.

\begin{tabular}{cll}
\hline & Nome comum & Espécie \\
\hline 1 & bagre & Netuma spp. \\
2 & cavalinha & Scomber japonicus \\
3 & corvina & Micropogonias furnieri \\
4 & galo & Selene setapinnis \\
5 & palombeta & Chloroscombrus chrysurus \\
6 & sardinha-lage & Opisthonema oglinum \\
7 & sardinha-verdadeira & Sardinella brasiliensis \\
Espécies com captura relativa média menor que 0,5\% do total \\
8 & cação & \# Espécies de 7 famílias \# \\
9 & carapau & Caranx crysos \\
10 & corcoroca & Orthopristis ruber \\
11 & enchova & Pomatomus saltatrix \\
12 & espada & Thrichiurus lepturus \\
13 & mistura & \\
14 & pampo & Trachinotus carolinus \\
15 & pargo & Pagrus pagrus \\
16 & paru & Pomacanthus arcuatus \\
17 & pescadinha & Macrodon ancylodon \\
18 & sardinha-cascuda & Harengula clupeola \\
19 & sororoca & Scomberomorus maculatus \\
20 & tainha & Mugil spp. \\
21 & xaréu & Caranx hippos \\
22 & xixarro & Trachurus lathami \\
\hline
\end{tabular}

nos meses de maio, setembro e outubro, respectivamente. Peixes demersais tiveram capturas expressivas neste ano, quando a corvina atingiu $22 \%$ dos desembarques em setembro, e o bagre $44 \%$ em julho e $10 \%$ em setembro. O peixe galo teve uma captura expressiva no mês de julho quando atingiu $9 \%$ do total desembarcado.

\section{Variação espaço-temporal das capturas}

A participação das diferentes espécies nas capturas é apresentada nas figuras 4 e 5 $\mathrm{a}-\mathrm{d}$, sendo que a ausência de dados (coluna) para determinado mês indica inexistência de informação.

\section{Setor 5a (Imbituba-Itajaí, até 40 m)}

Limite sul de ocorrência da espécie-alvo, este setor caracterizou-se pelo predomínio da sardinha-verdadeira (80-100\%) (Fig.4a). Em 1998, a sardinha-verdadeira ocorreu durante quase toda a temporada de pesca, sendo que nos meses de abril e junho representou quase $100 \%$ e em maio $20 \%$ do total capturado em peso. A partir de junho, sua participação diminuiu continuamente até setembro, atingindo $50 \%$ do total, aumentando para $75 \%$ no mês de novembro. Em maio a sardinha-lage atingiu $60 \%$ do total e entre os meses de julho e setembro, representou de $20 \%$ à $40 \%$ dos desembarques. Este mês caracterizou-se também pela ocorrência de espécies demersais como a corvina (40\%). No mês de outubro, o bagre representou $20 \%$ e a cavalinha $25 \%$ no mês de novembro. Em 1999, a sardinha-verdadeira atingiu até $100 \%$ das capturas e a sardinha-lage $80 \%$. Outras espécies capturadas merecem destaque: a palombeta no mês de maio $(20 \%)$, o xixarro em julho $(20 \%)$, bem como espécies demersais, como a corvina (35\%) e o bagre (25\%) em setembro (Fig.4a). Setor 5b (Imbituba-Itajaí, 40 à $80 \mathrm{~m}$ )

Em 1997 houve predomínio da sardinhaverdadeira neste setor, ainda que a espécie tenha ocorrido somente entre setembro e ou- 


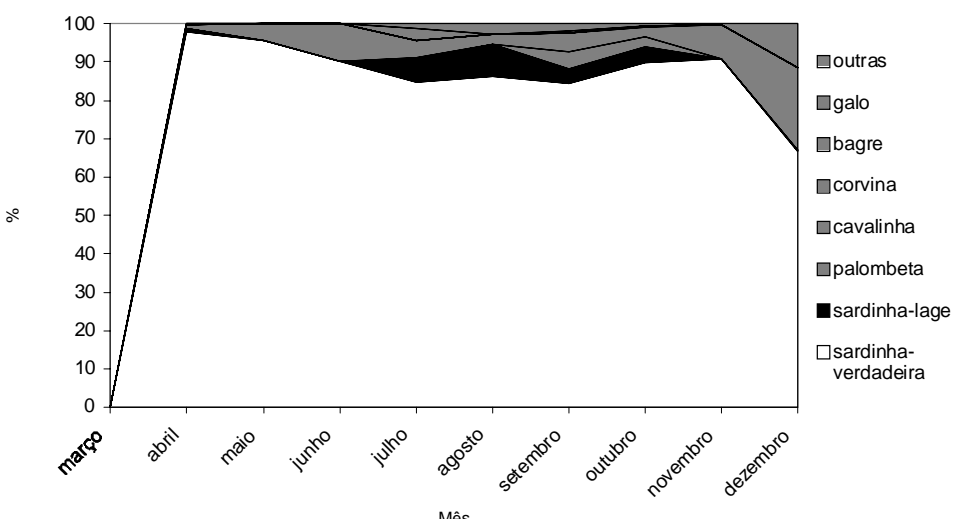

Mês

b

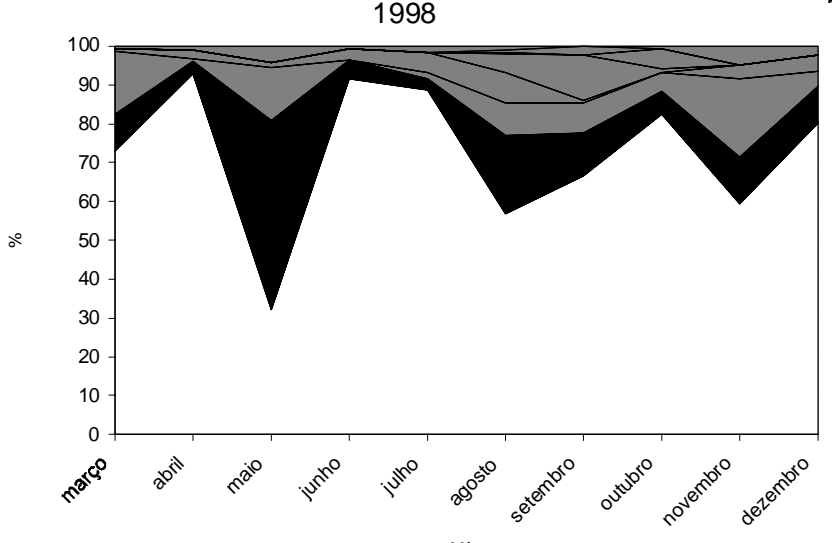

$\square$ outras

$\square$ galo

$\square$ bagre

$\square$ corvina

$\square$ cavalinha

$\square$ palombeta

- sardinha-lage

$\square$ sardinha-

verdadeira

Mês

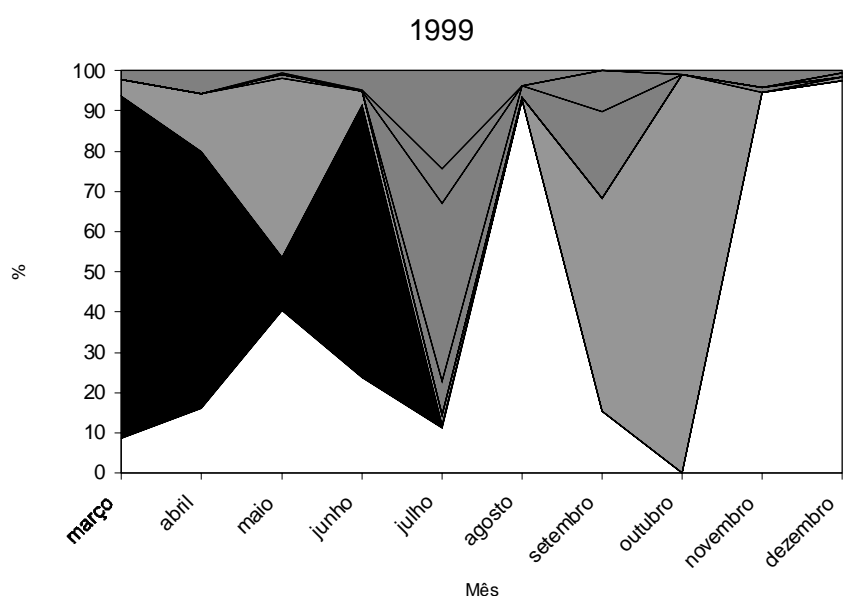

$\square$ outras

$\square$ galo

$\square$ bagre

$\square$ corvina

$\square$ cavalinha

$\square$ palombeta

@sardinha-lage

$\square$ sardinhaverdadeira

Figura 3a-c: Captura relativa mensal efetuada pela frota de traineiras que desembarcou no porto de Itajaí entre 1997 e 1999. 
tubro (75-100\%). O restante da captura foi composta pela cavalinha (Fig.5a). Em 1998, as capturas de sardinha-verdadeira neste setor concentraram-se entre abril e julho, atingindo quase $100 \%$ do total, sendo que a sardinha-lage representou $90 \%$ em maio. O mês de outubro deste ano caracterizou-se por uma significante captura de bagre (80\%). No ano de 1999 , a captura concentrou-se entre maio e junho e foi composta basicamente pela sardinha-verdadeira $(30-80 \%)$ e pela sardinha-lage (15-75\%).

Setor 6a (Itajaí-Cananéia, até 40 m)

Este setor apresentou capturas durante todo o período analisado (Fig.4b). Em 1997, houve o predomínio da sardinha-verdadeira nas capturas $(80 \%)$. Nos três primeiros meses de 1998 as espécies que mais se fizeram presente foram a sardinha-lage $(40-75 \%)$ e a palombeta (0-65\%). Capturas de cavalinha e corvina ocorreram entre de julho e setembro (10\%). O ano de 1999 apresentou uma tendência crescente nas capturas de sardinha-verdadeira de março à dezembro (10-95\%). A sardinha-lage representou $95 \%$ em março, decaindo para $20 \%$ em maio e ascendendo para $70 \%$ em junho. A palombeta que iniciou com valores inferiores à $10 \%$ em março, ascendeu até $100 \%$ dos desembarques no mês de outubro. Deve-se ressaltar que o mês de setembro caracterizou-se pela captura exclusiva de corvina $(100 \%)$.

\section{Setor 6b (Itajaí-Cananéia, 40 à 80 m)}

As capturas em 1997 fizeram-se presentes somente nos meses de julho, agosto e dezembro, quando a sardinha-verdadeira representou a maior parte das capturas (55-100\%) (Fig.5b). Capturas de cavalinha também ocorreram (20\%). O ano de 1998 apresentou ocorrência expressiva de sardinha-verdadeira entre abril e outubro (35-100\%). A sardinha-lage, de maio a agosto, alcançou de 5 a $55 \%$ do total em peso desembarcado. No ano de 1999, a pescaria ocorreu somente nos meses de maio, junho e dezembro, representado pela sardinhaverdadeira. A sardinha-lage compôs $40 \%$ das capturas em julho.

\section{Setor 7a (Cananéia-Santos, até 40 m)}

No ano de 1997 as capturas de sardinha-verdadeira foram representativas nos meses de julho, novembro e dezembro (80-100\%) (Fig.4c) e a palombeta representou $45 \%$ das capturas em setembro. No ano de 1998, a sardinha-verdadeira predominou nos desembarques em março e junho (80\%). Deve-se ressaltar que nos meses de setembro e outubro, a captura de palombeta foi de $100 \%$ e $60 \%$ respectivamente. O ano de 1999 predominaram as capturas de palombeta em maio e setembro (70-100\%) e sardinha-lage em maio (25\%).

\section{Setor 7b (Cananéia-Santos, 40 à 80 m)}

Em 1997, a sardinha-verdadeira representou mais de $90 \%$ das capturas entre abril e junho. Em dezembro a captura de cavalinha alcançou 60\% do total (Fig.5c). Em 1998 a sardinha-verdadeira foi capturada em maio e abril, quando esta representou quase $100 \%$ do total.

\section{Setor 8a (Santos-Ubatuba, até 40 m)}

Este setor apresentou capturas esporádicas de sardinha-verdadeira (Fig.4d), compondo $100 \%$ das capturas em novembro de 1997, e maio e setembro de 1998. Em setembro houve a presença de palombeta (15\%) nos desembarques. No ano de 1999, ocorreram capturas no mês de junho, as quais foram efetuadas sobre a cavalinha e galo. $O$ mês de setembro caracterizou-se pela captura de palombeta (100\%), e o mês de novembro pela ocorrência em partes iguais de sardinha-verdadeira e cavalinha (50\%). 
Setor 5a (Imbituba-Itajaí, até 40m)

a

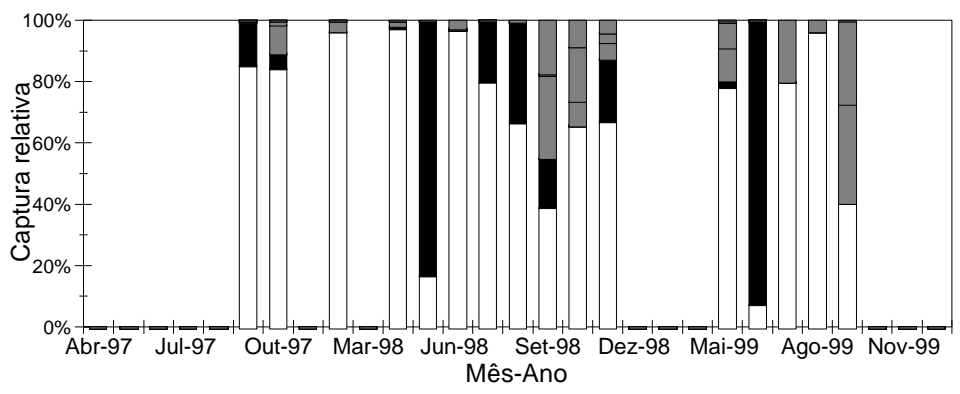

Setor 6a (Itajaí-Cananéia, até $40 \mathrm{~m}$ )

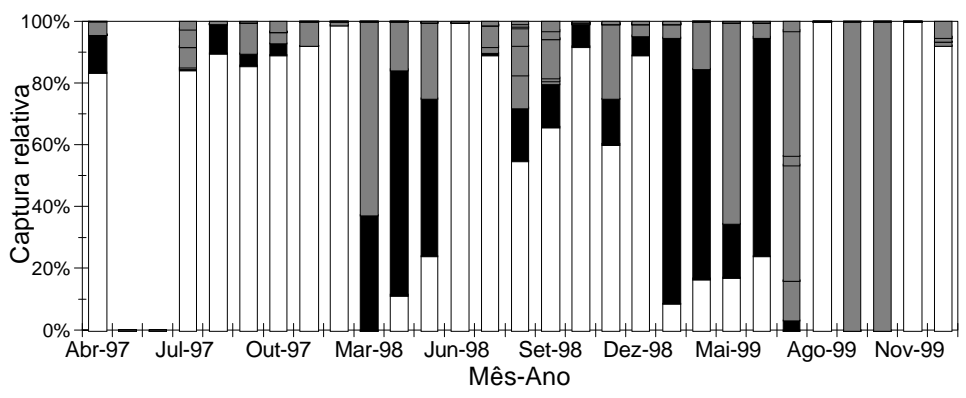

Setor 7a (Cananéia-Santos, até $40 \mathrm{~m}$ )

C

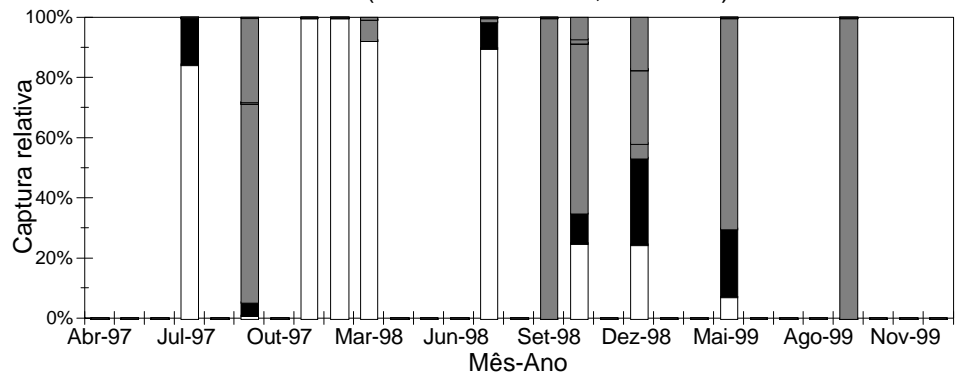

Setor 8a (Santos-Ubatuba, até $40 \mathrm{~m}$ )

d

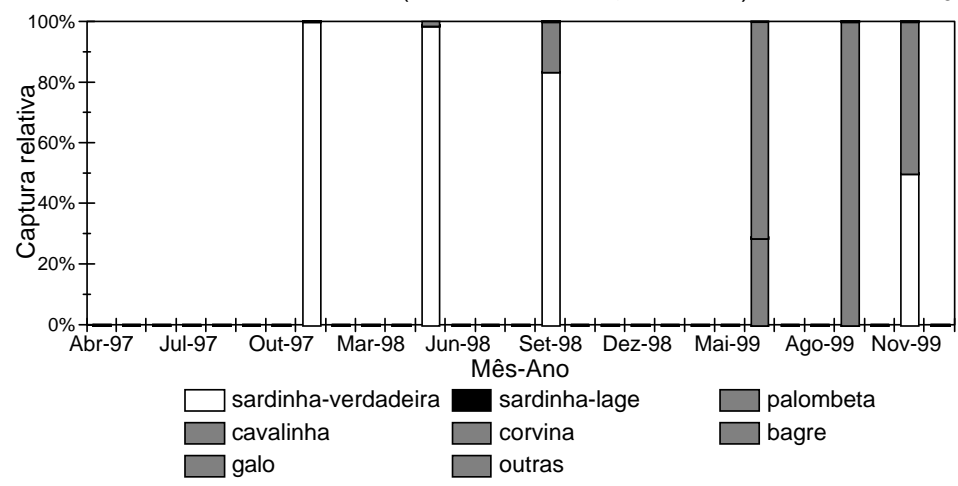

Figura 4a-d: Captura relativa mensal etetuada pela trota de traneıras nos setores ba a ya que desembarcaram no porto de Itajaí, entre 1997 e 1999. 
Setor 5b (Imbituba-Itajaí, 40 à 80 m)

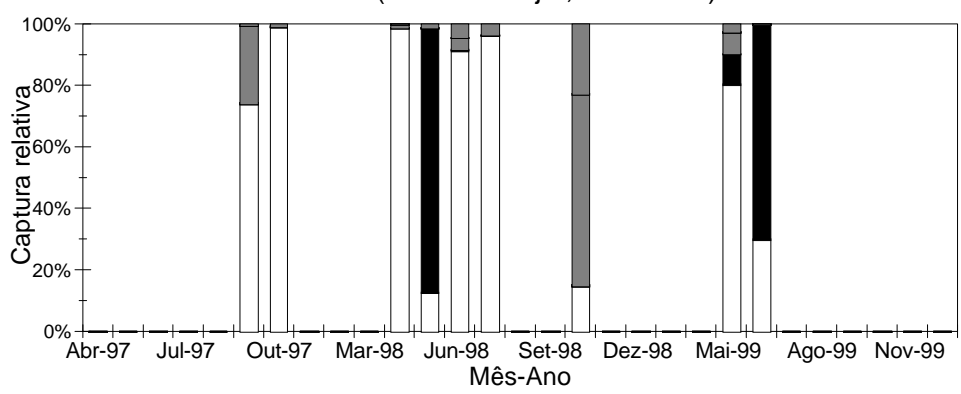

Setor 6b (Itajaí-Cananéia, 40 à 80 m)

b

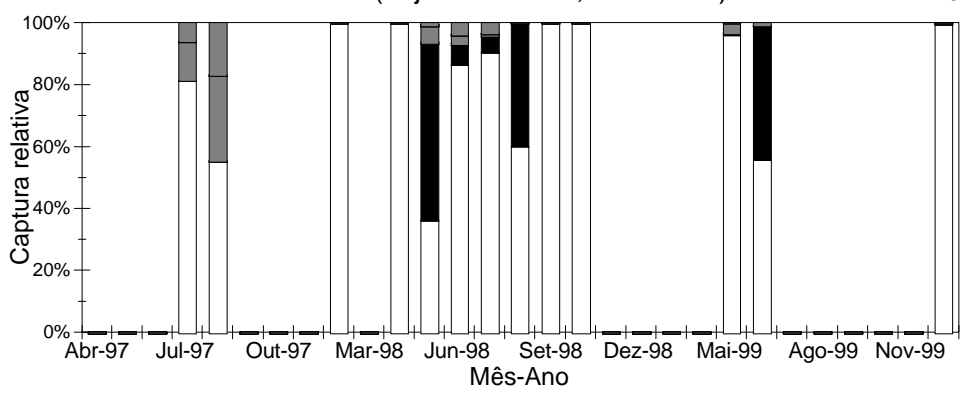

Setor 7b (Cananéia-Santos, 40 à $80 \mathrm{~m}$ )

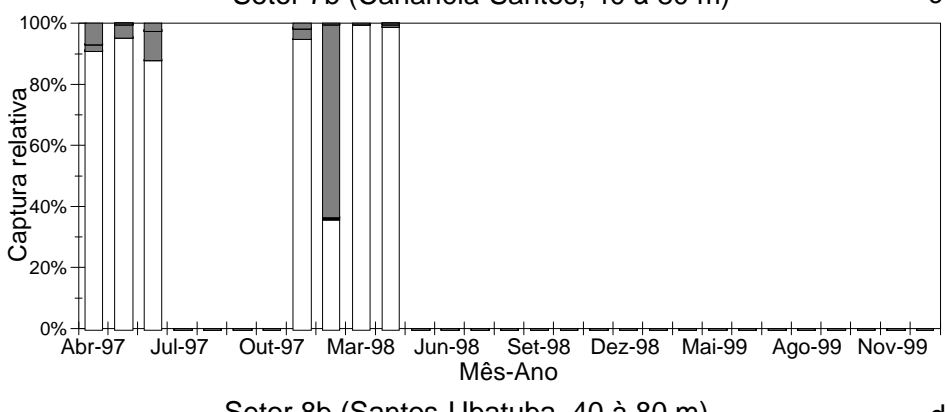

Setor $8 \mathrm{~b}$ (Santos-Ubatuba, 40 à $80 \mathrm{~m}$ )

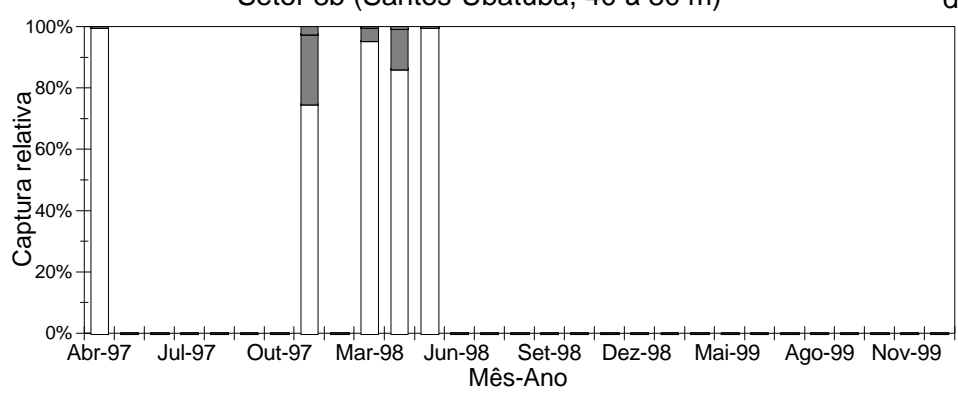

\begin{tabular}{|c|c|c|}
\hline sardinha-verdadeira & sardinha-lage & palombeta \\
\hline cavalinha & corvina & bagre \\
\hline galo & outras & \\
\hline
\end{tabular}

Figura 5a-d: Captura relativa mensal efetuada pela frota de traineiras nos setores $5 b$ à $8 b$ que desembarcaram no porto de Itajaí, entre 1997 e 1999. 
Setor $8 b$ (Santos-Ubatuba, 40 à 80 m),

A captura de sardinha-verdadeira foi efetuada somente nos meses de abril (100\%) e novembro (80\%) de 1997. O mês de maio de 1998 caracterizou-se por ser o último período de ocorrência da espécie-alvo neste setor, quando a mesma, compôs $100 \%$ das capturas (Fig.5d).

\section{DISCUSSÃO E CONCLUSÃO}

As capturas desembarcadas compunham-se por 21 espécies, entre elas, 7 foram destacadas como de maior importância. O ano de 1997 caracterizou-se pelo predomínio nos desembarques de sardinha-verdadeira seguido pela cavalinha. Espécies como a palombeta e sardinha-lage ocorreram somente entre os meses de julho e setembro. Para 1998 ocorreu uma diminuição da captura de sardinha-verdadeira e um aumento significativo na captura de sardinha-lage e palombeta. Isso ocorreu pois a espécie alvo da frota, a sardinha-verdadeira apresentou sinais de diminuição na disponibilidade. No ano de 1999, a sardinha-verdadeira continuou com uma tendência de queda nas capturas, o que pode indicar sinais de colapso do estoque. Por outro lado, as capturas de sardinha-lage e palombeta aumentaram. Em 1999, o destaque ficou para as significativas capturas de peixes demersais, como a corvina e o bagre.

Comparando-se os resultados do presente trabalho no tangente a composição da captura aos dos desembarques controlados pelo IBAMA (1994) no primeiro semestre de 1990, ano em que o estoque apresentou seus primeiros sinais de colapso e baixa captura de sardinha-verdadeira (32 mil t), observou-se que em 1997 e 1998 as médias anuais de participação da sardinha-verdadeira foram superiores às obtidas naquele ano. Entretanto, 1999 apresentou uma participação 14\% menor que 1990. Isto sugere que a captura atual de sardinhaverdadeira alcançou patamares mais baixos em termos relativos que naquele ano. Este fato corrobora as estimativas do total capturado para 1999 (aproximadamente 20 mil t), a mais baixa produção dos últimos 30 anos.

A variação espaço-temporal, identificada através da setorização da costa, indica variações na composição específica das capturas por setor. O setor 6a (Itajaí-Cananéia, 0-40m) é a área onde as capturas da frota de traineiras se concentraram entre 1997 e 1998. A sardinha-verdadeira predominou nas capturas dos diferentes setores no ano de 1997, entretanto, à partir de 1998 a pesca de cerco deixou de ser monoespecífica para se tornar gradualmente multiespecífica, atuando sobre outras espécies pelágicas, e.g. sardinha-lage, palombeta e cavalinha, bem como sobre espécies demersais, e.g. corvina e bagre. Além disso, a sardinha-verdadeira restringiu sua área de distribuição no período analisado, visto que a frota deixou de capturá-la nos setores 7 e 8 a partir de 1998, principalmente em profundidades superiores à 40m, o que provavelmente é devido à redução de biomassa disponível a pesca. Nos meses de novembro e dezembro ocorre um aumento na participação da sardinha-verdadeira nas capturas, provavelmente devido ao seu agrupamento junto à costa para posterior desova, o que ocasiona um aumento da vulnerabilidade deste recurso pesqueiro neste período.

Alguns padrões de ocorrência das espécies puderam ser constatados através da distribuição espaço-temporal das capturas. A sardinha-lage, espécie que passou a ser representativa a partir de 1998 ocorreu nos setores 5 e $6(10-80 \mathrm{~m})$, sendo seu limite norte de captura o setor $7 a$ (Cananéia-Santos, até 40 m). A palombeta, parece distribuir-se mais ao norte, a partir do setor 6 (Itajaí-Cananéia), entretanto, restringindo-se a profundidades menores que $40 \mathrm{~m}$. Esta espécie predominou nos desembarques dos meses de setembro e outubro, principalmente no ano de 1999. A cavalinha apresentou capturas esporádicas em todos os setores e em diferentes épocas do ano. A corvina passou a integrar os desembar- 
ques somente a partir de 1998, predominando em setembro nas capturas dos setores $5 \mathrm{a}$ e 6a (Imbituba e Cananéia, até $40 \mathrm{~m}$ ). $O$ bagre ocorreu somente em outubro de 1998 e setembro de 1999, exclusivamente no setor 5 (Imbituba-Itajaí). A distribuição do galo não apresentou nenhum padrão sazonal de ocorrência, entretanto suas capturas se deram entre Itajaí e Ubatuba em profundidades até $40 \mathrm{~m}$.

Assim, as flutuações na participação da sardinha-verdadeira nas capturas ao longo do ano, podem estar relacionadas com a área de pesca ou a disponibilidade da mesma. Por outro lado, a frota mostra uma tendência de residência em áreas que tradicionalmente proporcionam maiores rendimentos (setor 6a), seja pela abundância do recurso pesqueiro ou pela proximidade do porto, onde os riscos de prejuízos são menores.

\section{REFERÊNCIAS BIBLIOGRÁFICAS}

Andrade, H.A. 1998. A produção pesqueira industrial em Santa Catarina. Notas Tec. FACIMAR, 2: 1-6.

Castello, J.P. \& M. Haimovici. 1991. Simpósio da FURG sobre pesquisa pesqueira: comentários e recomendações. Atlântica, Rio Grande, 13 (1): 5-9.
IBAMA. 1994. Sardinha - Atuns e Afins. Relatório das reuniões dos grupos permanentes de estudos-GPE's. Coleção do Meio Ambiente. Série estudos pesca no 11. Brasília: 15-32.

IBAMA/CEPSUL. 1999. Informe da pesca extrativista marinha em Santa Catarina de 1997. Itajaí: 37p.

Matsuura, Y. 1996. A probable cause of recruitment failure of the Brazilian sardine Sardinella aurita population during the 1974/ 75 spawning season. S.Afr.J.mar.Sci.17: 29-35.

Matsuura, Y. 1998. Brazilian sardine (Sardinella brasiliensis) spawning in the southeast Brazilian Bight over the period 1976-1993. Rev. Bras. Oceanogr., 46(1): 33-43.

Nahum, V.J.I.; R.D. Cardoso; G. Servo \& C.L.B.R. Wongtschowski. 1988. Aspects of the spawning biology of the Brazilian sardine, Sardinella brasiliensis. J.Fish Biol. 32, 383-396.

Perez, J.A.A.; S.H.B. Lucato; H.A. Andrade; P.R. Pezzuto \& M. Rodrigues-Ribeiro. 1998. Programa de amostragem da pesca industrial desenvolvido para o porto de Itajaí, SC. Notas Tec. FACIMAR, 2: 93-108. 


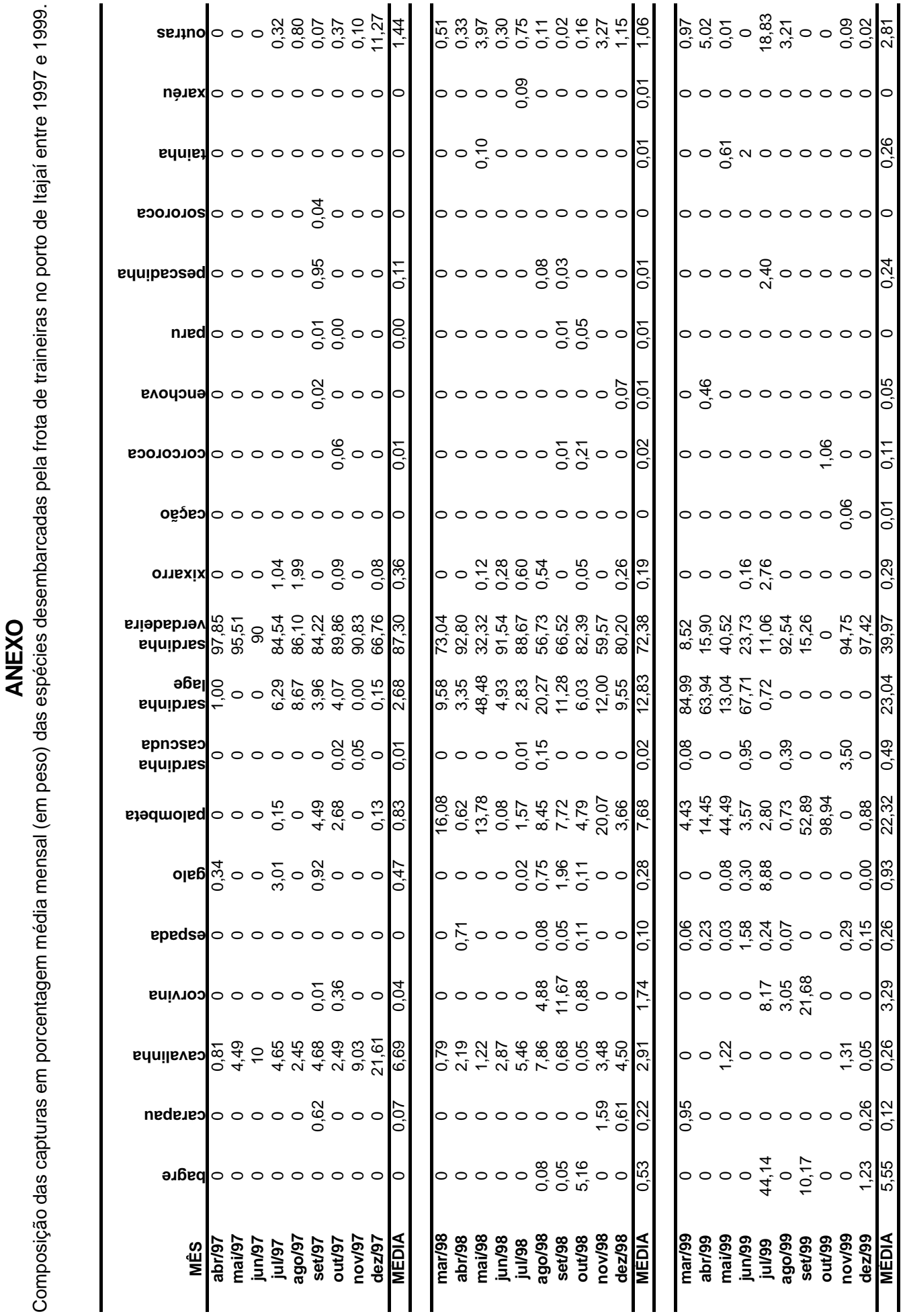

